\title{
QUALITY IMPROVEMENT Sustainability in quality improvement: measuring impact
}

\author{
Authors: Frances Mortimer, ${ }^{\mathrm{A}}$ Jennifer Isherwood, ${ }^{\mathrm{B}, \mathrm{C}}$ Michael Pearce, ${ }^{\mathrm{D}}$ Charlie Kenward ${ }^{\mathrm{E}}$ and Emma Vaux ${ }^{\mathrm{F}, \mathrm{G}}$
}

'Sustainable value' considers patient and population outcomes against environmental, social and economic costs or impacts, providing a framework for driving sustainable improvements in healthcare for current and future generations. Measuring the impact of a quality improvement initiative on sustainable value is a new endeavour. For this to be both meaningful and useful, we must balance academic rigour (using a reproducible methodology to capture the most relevant and important impacts) against pragmatism (working within the constraints of available time and data). Using case studies, we discuss how the different variables of sustainable value may be measured in practice.

KEYWORDS: Sustainability, quality, value, quality improvement

\section{Introduction}

We have argued (in Sustainability in Quality Improvement: redefining value in this issue $)^{1}$ for an expansion of the definition of value in healthcare to consider patient and population outcomes against a 'triple bottom line' of environmental, social and economic costs or impacts. By adopting this more holistic definition of value and using it to drive quality improvement efforts, we can support the evolution of ethical health services, which contribute positively to building health in communities and which can be sustained to provide high-quality care to patients not just of today but of the future.

It is increasingly well recognised that, due to the complex interplay of contextual and methodological factors, quality improvement initiatives do not necessarily produce the benefits that are intended. ${ }^{2}$ In response, the academic discipline of improvement research is now being developed, aiming to 'understand, help develop, and evaluate improvements to health

Authors: ${ }^{\text {A }}$ medical director, Centre for Sustainable Healthcare, Oxford, UK; ${ }^{\text {B }}$ clinical fellow in sustainability, Royal College of Physicians, London, UK; 'ST6 general surgical registrar, Health Education Thames Valley, London, UK; ${ }^{\text {ST5 }}$ registrar in general and older adult psychiatry, Oxford Health NHS Foundation Trust, Oxford, UK; E general practitioner, Bristol, UK; F consultant nephrologist and general physician, Royal Berkshire NHS Foundation Trust, Reading, UK; ${ }^{\mathrm{G}}$ senior censor and vice president education and training, Royal College of Physicians, London, UK

$$
\text { Value }=\frac{\text { Outcomes for patients and populations }}{\begin{array}{c}
\text { Environmental }+ \text { social }+ \text { financial impacts } \\
\text { (the 'triple bottom line') }
\end{array}}
$$

Fig 1. Sustainable value in healthcare. Reproduced with permission from Mortimer et al, 2018.

care practices and policies'. ${ }^{3}$ This presents a timely opportunity to embed sustainable value as a guiding framework for the future development of healthcare improvement. But how might one 'evaluate improvements' from a sustainability perspective?

In this article we aim to provide a starting point for developing sustainability evaluation in the context of quality improvement. Beginning with the sustainable value equation (Fig 1), we discuss how the different variables may be measured in practice.

\section{Measuring impact / measuring value}

Improvement projects are often planned using a logic model or logical framework, ${ }^{4}$ by which intended outcomes, outputs and activities are developed in support of a stated goal(s), along with objective indicators to allow evaluation at each level. Measuring impact as discussed here is distinct from the use of such processbased indicators to measure progress within a project, referring instead to the original goal of the improvement, which we have argued should be "to deliver maximum health gain with minimum financial cost and harmful environmental impacts, while adding social value at every opportunity'. This represents a significant broadening of focus for current quality improvement initiatives, many of which are driven by an exclusively clinical focus for a defined subpopulation (eg reducing morbidity and mortality from $X$ intervention in $Y$ patient group), ignoring population-level outcomes and value from resources. Where resource use is currently considered, this is almost universally restricted to the financial cost of providing care.

We propose that potential impacts (positive and negative) be considered for each of the five variables in the sustainable value equation and pragmatic outcome measures identified to capture the most important impacts in each category:

\footnotetext{
$>$ patient health outcomes

$>$ population health outcomes

$>$ environmental impacts

$>$ social impacts

$>$ financial impacts.
} 
In this multidimensional approach, we do not intend that all the outcome measures be converted into a common unit of measurement to enable the equation to be resolved as a single numerical value. Rather, the intention is to make visible the true costs and benefits at a system-wide level, to inform and drive improvements in each area.

Importantly, since value streams follow patient pathways and may cross organisational boundaries, when measuring value, we should do our best to look across the whole system, not just at individual steps within the patient pathway.

\section{Measuring patient and population outcomes}

Systematic measurement of comprehensive, patient-centred outcomes is a powerful tool for driving improvements in care. Outcomes are the results of care on the health of patients and populations and are distinct from interventions or processes involved in delivering care (which are more often measured, being easier to measure). ${ }^{6}$ The identification of standard outcome indicators for different medical conditions and patient groups is an ongoing endeavour. ${ }^{7,8}$ In a quality improvement project, a pragmatic approach is to establish a threshold of good quality based, where possible, on internationally agreed outcome measures. Following the improvement intervention, the service should meet or exceed the defined 'good quality' threshold, and any known harms / adverse effects should subsequently be subtracted to demonstrate a net effect.

Service provision should consider an entire population as well as the individual patient, aiming to meet the needs of all groups. Even an excellent service, if it only helps a few individuals, provides limited and unequal benefit. Therefore, data on relevant population-level outcomes should be obtained to provide context to the health outcomes achieved in the defined patient group, highlighting any unmet need.

\section{Measuring financial costs}

Health economics is an academic discipline in its own right with an entire published literature of its own. Many larger quality improvement programmes can call on health economists to help with economic evaluation of the costs of providing care as well as the economic impacts of ill-health or adverse events (although the application of health economics in this context is itself relatively immature). ${ }^{9}$ However, for those without access to academic support, guidance for calculating cost-benefit analysis can be found elsewhere. ${ }^{10}$

\section{Measuring environmental costs: carbon foot-printing}

Although not the only environmental consideration, climate change is recognised as the gravest and most urgent environmental threat to human health. A carbon footprint is the sum of greenhouse gas (GHG) emissions (which drive climate change) attributable to a given process, and is widely used as a measure of environmental impact.

The NHS is committed to meet carbon reduction targets of $34 \%$ by 2020 and $80 \%$ by 2050 (on a 1990 baseline), in line with the UK Climate Change Act of 2008. The impact of a quality improvement project on the NHS carbon footprint can be estimated by converting data on travel, consultations, hospital admissions or other activity into kilograms of carbon dioxide
Box 1. Case study 1: estimating financial and carbon impacts of a primary care-based QI project

A primary care team noticed some of their patients referred for hip and knee replacements were being referred back to the GP surgery after preoperative assessment at the local hospital because preoperative parameters, eg blood pressure, were either outside the target range or not communicated properly in the referral information. An audit of practice referrals revealed that one in six patients 'looped' through the system. In a typical year this would result in around 10 unnecessary referrals for one large practice.

The team implemented a quality improvement project to improve communication between the surgery and local hospital team by creating a new preop consultation template for use by the GPs and including the completed template with referrals. The goal was to reduce looping within the system and the attendant waste of resources.

Measuring impact: a typical 'waste loop' could result in an extra GP consultation and an extra hospital consultation. Using published data, standard values for both financial cost and carbon footprint were attached to each activity, in order to calculate the resources saved for every loop prevented: Costs of extra GP consultation: $£ 45,{ }^{11} 18 \mathrm{~kg} \mathrm{CO}_{2} \mathrm{e}^{12}$

Costs of hospital consultation: $£ 112,{ }^{11} 23 \mathrm{~kg} \mathrm{CO}_{2} \mathrm{e}^{12}$

Total financial and environmental savings for 10 referral loops avoided: $£ 1,570,410 \mathrm{~kg} \mathrm{CO} 2 \mathrm{e}$

Estimated value impact of project over 1 year $\Delta$ patient and population outcomes [not measured]

$410 \mathrm{~kg} \mathrm{CO}$ e saving + £1,570 saving + social impacts [time/stress etc - not measured]

equivalents $\left(\mathrm{CO}_{2} \mathrm{e}\right)$ using GHG 'emissions factors'. (Generic GHG emissions factors are published by the UK government, or alternatively, healthcare-specific guidance is available from the NHS Sustainable Development Unit.)

Carbon footprint $\left(\mathrm{kg} \mathrm{CO}_{2} \mathrm{e}\right)=$ activity or resource use $\times \mathrm{GHG}$ emissions factors

Case study 1 (Box 1) illustrates the measurement of financial and environmental impacts from a quality improvement project.

\section{Measuring social impacts}

There is no standardised methodology for measuring social impacts in the context of healthcare. Health services can influence the social circumstances of patients, carers, dependents, staff and communities both local and distant - such as those affected by activities in the supply chain. Impacts may also be diverse: affecting housing status, employment status or conditions, even social inclusion and relationships. ${ }^{13}$ Although there is not a simple formula, it is valuable to consider the range of people affected by a care system, the size and nature of any potential impacts from a service change and, where possible, their importance to the people concerned. Having identified impacts that are likely to be most relevant in a given care system, public health colleagues can often provide help in determining how these may be measured, and in accessing any existing available data. 
Table 1. Key themes of social sustainability ${ }^{a}$

$\begin{array}{ll}\text { Traditional } & \text { Emerging } \\ \begin{array}{l}\text { Basic needs, including housing } \\ \text { and environmental health }\end{array} & \begin{array}{l}\text { Demographic change (ageing, } \\ \text { migration and mobility) } \\ \text { Education and skills }\end{array} \\ \text { Employment } & \begin{array}{l}\text { Social mixing and cohesion } \\ \text { Identity, sense of place and culture }\end{array} \\ \text { Equity } & \begin{array}{l}\text { Empowerment, participation and } \\ \text { access }\end{array} \\ \text { Human rights and gender } & \begin{array}{l}\text { Health and safety } \\ \text { Poverty }\end{array} \\ \text { Social justice } & \begin{array}{l}\text { Social capital being, happiness and quality } \\ \text { of life }\end{array}\end{array}$

${ }^{a}$ Source: Colantonio A, Dixon T. Measuring socially sustainable urban regeneration in Europe. Oxford Institute for Sustainable Development, School of the Built Environment, Oxford Brookes University (2009) ${ }^{1 / 4}$ (reproduced with permission)

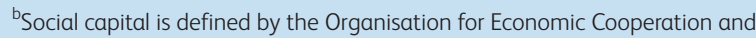
Development (OECD) as 'networks together with shared norms, values and understandings that facilitate co-operation within or among groups'

Table 1 lists key themes of social sustainability which can help to provide a structure when considering social impacts. Case study 2 (Box 2) illustrates a pragmatic approach to measuring the social impacts - in this case, of an existing service - on staff, patients and carers.

\section{Discussion}

Measuring the impact of improvement initiatives is central to the emerging discipline of improvement science, enabling effective strategies to be distinguished from ineffective or harmful ones. ${ }^{4}$ It is critical that impact measures be aligned to the overall goal

\section{Box 2. Case study 2: measuring social impact of a} dementia service

A 'triple bottom line' evaluation of a service providing a range of group activities for younger people with dementia considered its social impacts on staff, patients and carers. ${ }^{15,16}$

Staff sickness and turnover rates within the service were noted to be low, suggesting a sustainable use of staff resource.

Measures of patients' cognitive function and behavioural and psychological disturbance were used as proxies for social impact on patients and carers. These are known to be independent predictors of need for 24 -hour care. ${ }^{17}$ The evaluation found that, despite cognitive function deteriorating as would be expected in dementia, for people using the service, there was an improvement in distressing behavioural and psychotic symptoms. In addition, comparison with a small group of matched controls found a slower deterioration in cognition in those accessing the service than those not accessing it.

Carers' views were also sought regarding the value of the service to their relative's and their own wellbeing and providing carers with respite time. $77 \%$ of carers reported a benefit to their relative's wellbeing and $82 \%$ said they had gained respite time. of quality and value improvement. Current approaches tend to focus on clinical impacts chosen for their relevance to (and amenability to change by) specific services, which may not capture those impacts most important to patients, and may not reflect the care provided by the care system as a whole to all the people in need in a population. Meanwhile, the resource implications of improvement are poorly studied and almost universally limited to financial resources, ignoring environmental and social resource use. If outcomes are defined too narrowly, and the resource implications of change are not considered, then opportunities to improve the use of resources for patient and population benefit will continue to be missed.

We believe that adopting sustainable value as a guiding framework for improvement science will foster a more holistic, resource-based approach in healthcare improvement and inform the development of initiatives that build towards a sustainable future.

There is a need for balance between measuring what is important and overburdening those attempting to make improvements with data collection and analysis. We believe that giving thought to each variable in the sustainable value equation and how it could be measured and improved could become part of every improvement project, while full sustainability impact analysis will be research led.

Over time, as the framework is established in practice, we would expect that the proposed methodologies become more standardised for the different types of service and quality improvement intervention, reducing the burden on improvement teams and increasing their capacity to conduct meaningful impact evaluation.

\section{Conclusion}

The redefinition of value in healthcare to include environmental and social dimensions is necessary in order to support the creation of a more ethical, sustainable health service. To be meaningful, the new definition needs also to be measurable. We have provided guidance on how the different elements of sustainable value may be captured and quantified in the context of a quality improvement initiative. The multidimensional approach to measuring value provides a consistent yet flexible framework to highlight important impacts (such as effects on staff working conditions or patient time and travel) that have too often been disregarded - to the detriment of patients, services and communities.

\section{Author contributions}

FM was the main author and led on conception, design, data analysis and drafting. JI contributed to design and drafting. CK contributed to data acquisition and analysis, drafting and critical review. MP contribed to data acquisition and analysis, drafting and critical review. EV contributed to design and critical review. All authors gave final approval of the manuscript and agreement to accountability.

\section{References}

1 Mortimer F, Isherwood J, Wilkinson A, Vaux E. Sustainability in quality improvement: redefining value. Future Healthcare J, 2018:88-93.

2 Dixon-Woods M, Martin GP. Does quality improvement improve quality? Future Healthcare J 2016;3:191-4. 
3 The Health Foundation. Creating a new improvement research institute. http://www.health.org.uk/creating-new-improvementresearch-institute-0 [Accessed 7 August 2017].

4 Nancholas S. How to do (or not to do)... a logical framework. Health Policy Plan 1998;13:189-93.

5 Dixon-Woods M, McNicol S, Martin G. Ten challenges in improving quality in healthcare: lessons from the Health Foundation's programme evaluations and relevant literature. BMJ Qual Saf 2012;21:876-84

6 Porter ME. What is value in health care? N Engl J Med 2010;363:247781.

7 Porter ME, Larsson S, Lee TG. Standardizing patient outcome measurement. N Engl J Med 2016;374:504-6.

8 Alderwick H, Robertson R, Appleby J, Dunn P, Maguire D. Better value in the NHS. The role of changes in clinical practice. King's Fund, 2015.

9 de Rezende BA, Or Z, Com-Ruelle L, Michel P. Economic evaluation in patient safety: a literature review of methods. BMJ Qual Saf 2012:21:457-65.

10 Treasury HM. Supporting public service transformation: cost benefit analysis guidance for local partnerships. London: HM Treasury, 2014.

11 Personal Social Services Research Unit. Unit Costs of Health and Care 2015. PSSRU, 2015
12 Sustainable Development Unit. Carbon Hotspots update for the health and care sector in England 2015. Cambridge: SDU, 2016.

13 Littig B, Grießler E. Social sustainability: a catchword between political pragmatism and social theory. Int J Sustainable Development 2005;8:65-79.

14 Colantonio A, Dixon T. Measuring socially sustainable urban regeneration in Europe. Oxford Institute for Sustainable Development, School of the Built Environment, Oxford Brookes University, 2009.

15 Hussey J. Younger people - an innovative partnership. The Journal of Dementia Care 2016;24.

16 Maughan D, Lillywhite R, Pearce S, Pillinger T, Weich S. Evaluating sustainability: a retrospective cohort analysis of the Oxfordshire therapeutic community. BMC Psychiatry 2016;16:285.

17 Gaugler JE, Yu F, Krichbaum K, Wyman JF. Predictors of nursing home admission for persons with dementia. Med Care 2009:47:191-8.

Address for correspondence: Dr Frances Mortimer, Centre for Sustainable Healthcare, 287-91 Banbury Road, Oxford 0X2 7JQ, UK.

Email: frances.mortimer@sustainablehealthcare.org.uk
'This landmark report lays out in the starkest terms yet the devastating impact air pollution is having on our health, our economy and our society as a whole.'

\section{Every breath we take The lifelong impact of air pollution}

This major report plainly sets out the dangerous impact that air pollution has on our nation's health. Compiled by experts in medicine and environmental sciences, the report discusses the current evidence and draws up recommendations for action.

ISBN 978-1-86016-567-2 £15 including $p+p$ or free to download

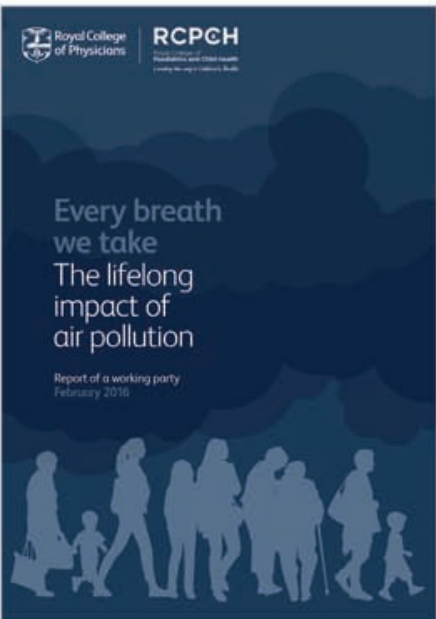

Order a copy:

shop.rcplondon.ac.uk
Download the report: rcplondon.ac.uk/pollution 